\title{
Anemia in patients with chronic kidney disease: current screening and management approaches
}

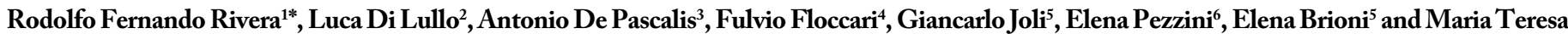 \\ Sciarrone Alibrandi ${ }^{5}$ \\ ${ }^{1}$ Division of Nephrology and Dialysis, San Gerardo Hospital, ASST Monza, Italy \\ ${ }^{2}$ Department of Nephrology and Dialysis, L. Parodi - Delfino Hospital, Colleferro, Rome, Italy \\ ${ }^{3}$ Division of Nephrology and Dialysis, Vito Fazzi Hospital, Lecce, Italy \\ ${ }^{4}$ Division Nefrologica e Dialisi, Ospedale San Paolo, Civitavecchia, Italy \\ ${ }^{5}$ Division of Nephrology, Dialysis and Hypertension, IRCCS San Raffaele Hospital, Milan, Italy \\ ${ }^{6}$ Department of Health Sciences, University of Milan Bicocca, Italy
}

\begin{abstract}
Anemia refers to an absolute reduction of the total number of circulating red blood cells (RBC), resulting in a reduction of hemoglobin (Hb) concentration. Anemia is a frequent complication in chronic kidney disease (CKD), and it is often accompanied by various clinical symptoms.

The primary cause of anemia in CKD patients is the reduction in the erythropoietin production, which results in a decrease of signaling molecule that stimulates red blood cell production. Other possible causes of anemia in CKD include iron deficiency, inflammation, and the accumulation of uremic toxins.

This chapter focuses the discussion on the strategy of the management of anemia in patients with CKD.

Erythropoiesis-stimulating agents (ESAs) and adjuvant iron therapy represent the primary treatment for anemia in chronic kidney disease. The introduction of ESAs into clinical practice was a success goal, mediating an increase in hemoglobin concentrations without the risk for recurrent blood transfusions and improving quality of life substantially.
\end{abstract}

\begin{abstract}
Abbreviations: $\mathrm{RBC}$ : red blood cells; $\mathrm{Hb}$ : hemoglobin; $\mathrm{Ht}$ : hematocrit; RBC: red blood cells; CBC: Complete blood count; CKD: chronic kidney disease; ESRD: end-stage renal disease; RRRT: required renal replacement therapy; HD: hemodialysis; PD: peritoneal dialysis; TSAT: Serum transferrin saturation; CKD: chronic kidney disease; EPO: endogenous erythropoietin; ESA: erythropoietic-stimulating agents.
\end{abstract}

\section{Introduction}

The World Health Organization (WHO) has defined anemia as an absolute reduction of the total number of circulating red blood cells (RBC) resulting in a reduction of hemoglobin concentration $<13.0 \mathrm{~g} /$ $\mathrm{dL}$ for adult males and postmenopausal women and an $\mathrm{Hb}<12.0 \mathrm{~g} /$ $\mathrm{dL}$ for premenopausal women [1]. For practical purposes, anemia is considered when one or more of the following are decreased: hemoglobin $(\mathrm{Hb})$, hematocrit $(\mathrm{Ht})$, or red blood cell (RBC) count.

In general, anemia is more common in women, in particular, those in their childbearing years. During the late decades of life, anemia tends to occur without any particular sex predilection. There has been a lower prevalence of anemia in current smokers, which has been attributed to secondary erythrocytosis.

Anemia is a frequent complication in chronic kidney disease (CKD), and it is often accompanied by various clinical symptoms, such as impaired physical capacity, decreased neurocognitive function, and poor quality of life [2]. However, males patients with CKD have a $30 \%$ greater risk of developing anemia as compared to their female counterparts. Although males have higher Hb values, they also have higher rates of advanced CKD.

One of the less known functions of the kidneys is the production of erythropoietin, a signaling molecule that stimulates red blood cell production, in response to decreased oxygen levels in the blood. Any disruption of this process, e.g., secondary to a functional abnormality due to $\mathrm{CKD}$, has the potential to induce anemia, a condition in which the number of circulating red blood cells, and therefore the level of $\mathrm{Hb}$, is lower than normal [3]. Other possible causes of anemia in CKD include iron deficiency, inflammation, and the accumulation of uremic toxins $[1,3]$. Thus, the abnormal composition of blood or urine is an additional indicator of kidney damage.

Based upon the WHO anemia diagnostic criteria, nearly 90 percent of patients with a glomerular filtration rate (GFR) $<25$ to $30 \mathrm{~mL} / \mathrm{min}$ have anemia, many with $\mathrm{Hb}$ levels $<10 \mathrm{~g} / \mathrm{dL}$ [4].

An observational study that included patients with selected comorbid conditions such as CKD, human immunodeficiency virus,

Correspondence to: Rodolfo F Rivera, Division of Nephrology and Dialysis, San Gerardo Hospital, ASST Monza, Italy, Tel: +390392334304; E-mail: rodolfofrivera@gmail.com

Key words: CKD, anemia, iron, erythropoiesis-stimulating agents, blood transfusions

Received: March 20, 2016; Accepted: April 15, 2016; Published: April 20, 2016 
rheumatoid arthritis, inflammatory bowel disease, congestive heart failure, and solid-tumor cancers, showed that among end-stage renal disease (ESRD) patients who required renal replacement therapy (RRRT), 68\% had a hematocrit (Ht) less than $30 \mathrm{mg} / \mathrm{dL}$ and $51 \%$ a $\mathrm{Ht}$ less than $28 \mathrm{mg} / \mathrm{dL}$ [5]. Furthermore, although anemia is not as common in earlier stages of CKD, patients with stage III disease have a prevalence of concurrent anemia of $5.2 \%$, whereas those with stage IV disease the prevalence of concurrent anemia is $44.1 \%$ [6].

Age and race are important risk factors for the development of anemia in CKD patients. There is a greater prevalence of anemia in those older than 60 years, as compared to those aged between 46 and 60 years. This is probably due to the greater CKD prevalence in older individuals, as well as the lower estimated GFR that are associated with aging. Black people have not only a 4 -fold increased risk of developing CKD relative to white persons [7] but also an increased prevalence of anemia.

From a clinical point of view, anemia has also been involved as a contributing factor in many of the symptoms associated with CKD, including fatigue expression, reduced exercise tolerance, dispnea, with cognitive impairment, sleep disturbances, increase in CKD rate progression, cardiovascular consequences, such as left ventricular hypertrophy (LVH) and left ventricular systolic dysfunction [8]. It is also associated with an increased risk of morbidity and mortality, principally due to cardiac disease and stroke [9-11], and with an increased risk of hospitalization, hospital length of stay, and mortality in patients with predialysis CKD $[12,13]$. On the other hands, direct healthcare costs are higher in CKD patients with anemia than in those without [3], and quality of life issues (e.g., fatigue, reduced productivity) are common. For all those reasons anemia deserves to be treated as one of the major complications or CKD.

\section{Diagnosis and evaluation of anemia in CKD}

Anemia is an initial laboratory sign of an underlying clinical problem in patients with or without CKD, for which is necessary a complete blood count, that include total $\mathrm{RBC}$ count, $\mathrm{Ht}$, and $\mathrm{Hb}$ concentration.

In patients with CKD but stable kidney function, the onset or the progression of anemia may predict a new clinical problem which could be the expression of a blood loss or interference with red cell production.

For this reason, anemia should be evaluated independently of CKD stage in order to identify any reversible process contributing to the anemia. There is a large list of causes and approaches to the diagnosis that can be found in a standard textbook of medicine or hematology useful for the clinical general practitioner. However, the causes of acquired anemia are myriad and too many to follow all steps of internistic guideline. A comprehensive list of this causes and diagnostic approach is desirable for CKD patients. The most commonly encountered reversible cause of worsening anemia in CKD patients, other than anemia directly related to $\mathrm{CKD}$, is iron deficiency.

CKD patients show a gradual decrease in $\mathrm{Hb}$ levels that usually is related to the decline in the GFR, suggesting the need for regular monitoring $\mathrm{Hb}$ concentration. As renal function declines in patients with more advanced CKD stages, the incidence and prevalence of anemia increases. Therefore, in order to identify CKD patients at high risk for therapeutic intervention, $\mathrm{Hb}$ concentration monitoring should be more frequent in proportion to CKD stages.
The frequency of $\mathrm{Hb}$ monitoring, regardless of $\mathrm{CKD}$ stage, should be influenced by both $\mathrm{Hb}$ level and rate of decline in $\mathrm{Hb}$ level. Monthly monitoring of $\mathrm{Hb}$ concentration is recommended in patients undergoing dialysis replacement therapy (HD hemodialysis or PD: peritoneal dialysis). It is important to remember that for HD patients $\mathrm{Hb}$ monitoring is traditionally performed prior to a midweek HD session, while this is not essential in PD patients. As in all patients, $\mathrm{Hb}$ testing should be performed whenever clinically indicated, such as after a major surgical procedure, hospitalization, or bleeding episode.

Initial evaluation of the anemia in $\mathrm{CKD}$, regardless of age and CKD stage, shoud include the following tests: Complete blood count (CBC), that should include $\mathrm{Hb}$ concentration, red cell indices, white blood cell count and differential, and platelet count; Absolute reticulocyte count; Serum ferritin level; Serum transferrin saturation (TSAT); Serum vitamin B12 and folate levels

\section{Complete blood count (CBC)}

CBC gives important information about the kinds, numbers and form of blood cells as well as red blood cells, white blood cells and platelets. CBS also provides information about both the severity of anemia and adequacy of bone marrow function. Since anemia of CKD is hypoproliferative, and in general, normochromic and normocytic, from the morphological point of view it is indistinguishable from the anemia of chronic disease [14]. Detection of macrocytosis may suggest folate or vitamin B12 deficiencies, whereas the presence of microcytosis is associated with iron deficiency or inherited disorders of $\mathrm{Hb}$ formation. Iron deficiency, especially if longstanding, is associated with hypochromia and macrocytosis with leukopenia or thrombocytopenia suggests a generalized disorder of hematopoiesis caused by toxins (e.g., alcohol), nutritional deficit (vitamin B12 or folate deficiency), or myelodysplasia. In the presence of one or more of these findings, further diagnostic evaluation are indicated. Abnormalities of the white blood cell count and differential or platelet count are not typical of $\mathrm{CKD}$ anemia. These alteration require investigation for other diseases. In CKD patients who have active blood loss or hemolysis, reticulocyte count may be high.

\section{Hemoglobin $(\mathrm{Hb})$ and hematocrit $(\mathrm{Ht})$ concentration}

$\mathrm{Hb}$ or $\mathrm{Ht}$ target in CKD or ESRD patients, would be defined as that value that is clinically optimal for each patient, based upon their special circumstances, such as general level of function and employment and comorbidities, such as coronary artery disease (CAD) and chronic heart failure (CHF).

Increasing evidence indicates the poor advantage, and even potential risk, with increased morbidity and mortality associated with targeting and maintaining $\mathrm{Hb}$ levels $>13 \mathrm{~g} / \mathrm{dL}$ in predialysis patients. According with most recent recommendation, clinicians should weigh the risk-benefit of erythropoietic-stimulating agents (ESA) therapy between decrease the need for transfusions against the increased risks for serious, adverse cardiovascular events. For each patient should be found minimum dosage of ESA to use sufficient to reduce the need for blood transfusions.

Although $\mathrm{Hb}$ target range is not provided, non-dialysis-dependent CKD (CKD-5 no D) patients should maintain Hb levels between 10.0 and $11.5 \mathrm{~g} / \mathrm{dL}$, and reduce or stop the treatment if the level exceeds this limits. For dialysis-dependent CKD (CKD-5 D) patients the level of $\mathrm{Hb}$ should be $<10 \mathrm{~g} / \mathrm{dL}$, and reduce or stop the treatment if Level, $\mathrm{Hb}$ or exceeds $11 \mathrm{~g} / \mathrm{dL}$ [15]. According to the major randomized trials, there are non benefits of $\mathrm{Hb}$ concentration between 11.5 and $13.0 \mathrm{~g} /$ 
$\mathrm{dL}$, and $\mathrm{Hb}$ targets $>13 \mathrm{~g} / \mathrm{dL}$ were associated with adverse outcomes [16-19]. There is now general agreement that in patients with CKD and ESRD, an adequate $\mathrm{Hb}$ target for anemia improves physiologic and clinical parameters and quality of life, compared with the very low $\mathrm{Hb}$ levels that were common prior to the availability of ESAs [15,20-23]. The National Kidney Foundation (NKF) Dialysis Outcomes Quality Initiative (DOQI) guidelines for the anemia of CKD were initially published in 1997, with revisions in 2001 and 2006 [20-22]. The 2007 update recommended than the range of 11 to $12 \mathrm{~g} / \mathrm{dL}$ of $\mathrm{Hb}$ target in all CKD patients, while $\mathrm{Hb}$ levels should never exceed $13 \mathrm{~g} / \mathrm{dL}$ [23]. The 2012 Kidney Disease Improving Global Outcomes (KDIGO) guidelines [24] recommended that CKD-5 D patients should maintain $\mathrm{Hb}$ concentrations $\geq 10 \mathrm{~g} / \mathrm{dL}$. In patients with $\mathrm{Hb}<10 \mathrm{~g} / \mathrm{dL}$, therapy should be individualized based upon the rate of fall in $\mathrm{Hb}$ concentration, the response to iron therapy, the risk transfusion, the risks related to ESA therapy, and the presence of symptoms. In no CKD-5 D patients, KDIGO suggests initiating therapy when the Hb concentration is $<10$ $\mathrm{g} / \mathrm{dL}$.

\section{Iron status}

Adequate iron stores are essential to optimize the effects of ESA, such as recombinant human erythropoietin (EPO) or darbepoietin alfa. In fact, decreased iron stores or decreased availability of iron represent the most common cause of resistance to the effect of EPO agents agents. An ideal test to evaluate iron status in CKD patients would accurately indicate whether the patient has sufficient amount of iron available to support achievement and maintenance of $\mathrm{Hb}$ target, and an excessive amount of body iron.

Unfortunately, no test exists with accomplishes either of these goals and which is practical to administer. Currently, the two best test of iron status are the serum ferritin and the present transferrin saturation (TSAT).

Serum ferritin is the most widely used test for the assessment of storage iron, for which the 'gold standard' remains the examination of a bone marrow aspiration stained for iron [25]. However, serum ferritin values have to be interpreted with caution in CKD patients since it may be affected by inflammation or malnutrition, especially in dialysis patients in whom subclinical inflammation may be present [26]. Serum ferritin values $<30 \mathrm{mg} / \mathrm{L}$ is indicative of severe iron deficiency and are highly predictive of absent iron stores in bone marrow $[27,28]$.

According to NKF-KDOQI Clinical Practice Guidelines for Anemia in $\mathrm{CKD}$, the recommended serum ferritin target to iron therapy in CKD-5 D patients should be $>200 \mathrm{ng} / \mathrm{mL}$, while in CKD-5 no $\mathrm{D}$ patients $>100 \mathrm{ng} / \mathrm{mL}$. CKD- $5 \mathrm{D}$ patients with a ferritin target up to $400-\mathrm{ng} / \mathrm{mL}$ showed a final ESA doses $28 \%$ lower than those in the lower $(200-\mathrm{ng} / \mathrm{mL})$ ferritin group, suggesting that higher ferritin target is well tolerated and reduce reduces the requirements for ESA [29].

There is no current evidence available to support treating most patients with serum ferritin levels greater than $500 \mathrm{ng} / \mathrm{mL}$. A therapeutic response to iron therapy in a patient with a ferritin level greater than $500 \mathrm{ng} / \mathrm{mL}$ is unlikely.

The percent TSAT (serum iron multiplied by 100 and divided by total iron binding capacity: TIBC) reflects iron that is readity available for erythropoiesis. The TIBC measures circulating transferring. The transferrin molecule contains two binding sites for transporting iron from storage sites to red progenitor cells. A TSAT of 50\% indicate that half of the binding sites are activated by iron.
The distinction between absolute and functional iron deficiency is essential to understanding what constitutes adequate TSAT \& circulating ferritin concentrations in ESA-treated CKD patients. In normal subjects, iron deficiency is considered "absolute" when iron store is depleted (circulating ferritin levels $<12 \mathrm{ng} / \mathrm{mL}$, and iron delivery is impaired as indicated by TSAT below $16 \%$ ). Absolute iron deficiency in CKD patients has been defined as a circulating ferritin values $<100$ $\mathrm{ng} / \mathrm{mL}$ and TSAT levels lower than $20 \%$. Differently, functional iron deficiency results when there is a need for a greater amount of iron to support hemoglobin synthesis than can be released from iron stores. This clinical situation can be observed in a chronic pharmacological stimulation with ESA in CKD patients with adequate iron stores, and it is characterized by a reduction in TSAT percent despite normal or elevated circulating levels of ferretin [27,28]. A TSAT lower than $20 \%$ in CKD-5 D patients has been traditionally considered to be an indicator of iron deficiency.

A common clinical problem is distinguishing between functional iron deficiency and inflammatory iron block, since the TSAT could be above the $20 \%$ and circulating ferritin could be 100 to $700 \mathrm{ng} / \mathrm{mL}$ in both clinical situations. During functional iron deficiency, ESA treatment induces a decrease in circulating ferritin levels, which however remain elevated (generally more than $100 \mathrm{ng} / \mathrm{mL}$ ). In contrast, inflammatory process is characterized by an abrupt increase of serum ferritin levels, that is associated with a sudden drop in the TSAT. Measurement of high sensitivity C-reactive protein (CRP) may be indicated if occult inflammation is a concern. In this situation, no further intravenous (IV) iron should be administrated until the inflammatory condition has resolved.

Reticulocyte count can be obtained with automated $\mathrm{CBC}$ testing, and may be high in patients who have active blood loss or hemolysis, and may be low in hypoproliferative erythropoiesis with anemia.

Other tests of iron status, such as percentage of hypochromic red blood cells and reticulocyte $\mathrm{Hb}$ content may be used instead of, or in addition to, TSAT and ferritin levels if available.

Hepcidin is a recently discovered peptide hormone regarded as the key regulator of iron entry into the plasma [30], is up-regulated by inflammation and increased iron stores and down-regulated by iron depletion. Hepcidin blocks iron release from the macrophages, limiting iron availability for erythropoiesis. Elevated serum levels of the bioactive hepcidin isoform, have been consistently reported in CKD$5 \mathrm{D}$ patients $[31,32]$ however, determination of circulating hepcidin levels has not been shown to be clinically useful or superior to more standard iron status tests in patients with CKD [33].

Folate and vitamin B12 deficiency are uncommon but important causes of treatable anemia, typically associated with macrocytic red blood cell (RBC) indices. The prevalence of vitamin B12 and folate deficiency in CKD-5 D patients is about $10 \%$, and limited data are available in CKD-5 no D patients. Nonetheless, since these deficiencies are easily correctable, and in the case of vitamin B12 may indicate other underlying disease processes, assessment of folate and vitamin B12 levels are generally considered standard components of anemia evaluation, especially in the presence of macrocytosis.

\section{Use of iron to treat anemia in CKD}

Iron is an essential mineral for heme synthesis, and adequate amounts of it are required for the production of new erythrocytes. Erythropoietic stimulation during anemia treatment in CKD patients, induces a greater utilization of iron available to satisfy the 
increased demands of the bone marrow. Under these conditions, the amount of iron usable could become inadequate [34]. Therefore, iron supplementation in CKD patients with anemia is used to assure adequate iron stores for erythropoiesis, correct iron deficiency, and, prevent iron deficiency from developing in those patients receiving ESA treatment. Correction of iron deficiency with oral or intravenous iron supplementation can reduce the severity of anemia through the improve of erythropoietic response to ESA treatment [35,36].

Iron supplementation, particularly with intravenous iron, can increase erythropoiesis and raise $\mathrm{Hb}$ levels even when TSAT and ferritin circulating values are not indicative of absolute iron deficiency, and when bone marrow studies reveal adequate iron stores [37-39].

Due to the limited diagnostic utility of serum ferritin and TSAT test to estimate body iron stores, prescription of iron therapy in patients with $\mathrm{CKD}$ is complicated, which makes it difficult to predicting a $\mathrm{Hb}$ response to iron supplementation [40].

The prescription of iron therapy should be based on an assessment that an increase in $\mathrm{Hb}$ level is desirable in order to avoid transfusion or reduce the symptoms of anemia related. In addition, the potential adverse effects of iron supplementation should be considered taking into account appropriately outweighed by the expected treatment benefit.

Iron supplementation could be in the form of oral or intravenous (IV) while the use of intramuscular iron has largely been abandoned. Each administration route has its own potential advantages and disadvantages.

Oral iron is less expensive, readily available, and does not require IV access, a particular concern in non dependent-HD CKD patients. Despite oral route is generally well tolerated and it is not associated with severe adverse effects, gastrointestinal side effects such as nausea, dyspepsia and diarrhea are common and may limit adherence [41]. In addition, variable gastrointestinal tract absorption associated with gastrointestinal intolerance, can affect the treatment efficacy, penalizing the choice of this route of administration.

IV iron avoids concerns about medication adherence and efficacy in treating iron deficiency, but requires IV access and has been associated with infrequent but severe adverse reactions. The most dangerous adverse reaction to IV iron treatment is anaphylaxis, which is the most serious expression of hypersensitivity reactions (HSR) [42]. HSR are quite rare but they could be fatal if not managed promptly [43]. They used to be more common with older formulations of high molecular weight iron dextran (HMW-ID) than with newer preparations [4446]. Similar to iron dextran, new iron molecules with large molecularweight have been developed. Given the reduced amount of free iron released following administration, they may have an improved safety profile. However, post-marketing data are still inadequate to draw definitive conclusions and new molecules may be object of over reporting.

The optimum route of iron administration in CKD patients is still controversial. IV iron is more effective than oral iron in HD patients in replenishing iron stores, achieving a sustained $\mathrm{Hb}$ response, reducing the need for red blood cell transfusions [47], and reducing the required dosage of ESA [48-51]. In non-dialysis dependent CKD patients there is no widely accepted consensus on whether IV or oral iron should be used as first-line therapy in CKD-related anemia. Despite the potential benefits of oral iron, that include the low cost and the easy administration, its use is limited by poor gastrointestinal adsorption and high rate of adverse events [41,52-54].

Oral iron is typically prescribed to provide approximately $200 \mathrm{mg}$ of elemental iron daily. Oral administration should be given between meals (e.g., 2 hours before or 1 hour after a meal). For patients who have difficulty tolerating oral iron supplements, it is possible prescribe smaller, more frequent doses; start with a lower dose and increase slowly to the target dose; try a different form or preparation; or take at bedtime. Dosage of oral iron expressed in terms of elemental iron are shown in Table 1.

In same CKD patients, daily smaller doses of oral iron may be useful and better tolerated. Although ferrous sulfate is commonly available and inexpensive, other oral iron preparations may also be used; there is not significant evidence to suggest that other oral iron formulations are more effective or associated with fewer adverse side effects than ferrous sulfate. If the goals of iron supplementation are not met with a $1-3$ month course of oral iron, it is appropriate to consider IV iron supplementation.

Iron dextran (ID) formulations carry a black box warning about fatal anaphylactic reactions, likely because of antibodies to the ironcarbohydrate or ID complex or the dextran component, particularly with high-molecular-weight ID (HMW-ID). The introduction of low-molecular-weight ID (LMW-ID) substantially reduces the risk of anaphylaxis. With ID therapy, test doses are required, along with an observation period for antibody reactions. Newer IV irons ferric gluconate and iron sucrose, that do not contain dextran, have a better safety profile. Chertow et al. [55] compared absolute rates of life-threatening HSR reported by the FDA from 2001 to 2003. For four different parenteral iron preparations (iron sucrose, ferric gluconate, LMW-ID, and HMW-ID), HSR were $0.6,0.9,3.3$, and 11.3 per million patients, respectively. Ferumoxytol is the newest IV iron formulation to enter in the market [56]. It is a superparamagnetic iron oxide nanoparticle coated with a low molecular weight semisynthetic carbohydrate. It helps to isolate the bioactive iron from plasma components until the iron-carbohydrate complex enters the reticuloendothelial system macrophages of the liver, spleen and bone marrow. The iron is released from the iron-carbohydrate complex within vesicles in the macrophages. Iron then either enters the intracellular storage iron pool (e.g., ferritin) or is transferred to plasma transferrin for transport to erythroid precursor cells for incorporation into hemoglobin. Dosage of IV iron, expressed in terms of elemental iron are shown in Table 2.

\section{Use of erythropoietic-stimulating agents to treat anemia in CKD}

The main cause of anemia in CKD is a loss of kidney endogenous erythropoietin (EPO) production capacity, but more recently other conditions able to aggravate this effect have been proposed, such as a derangement in oxygen sensing [57]. The introduction of recombinant human erythropoietin (rHuEPO) into clinical practice in the 1980s

Table 1. Approximate elemental iron content of various oral iron preparations.

\begin{tabular}{|c|c|}
\hline Drug & Elemental Iron \\
\hline Ferric pyrophosphate & $120 \mathrm{mg} / \mathrm{g}$ \\
\hline Ferrous gluconate & $120 \mathrm{mg} / \mathrm{g}$ \\
\hline Ferrous sulfate & $200 \mathrm{mg} / \mathrm{g}$ \\
\hline Ferrous sulfate, dried & $300 \mathrm{mg} / \mathrm{g}$ \\
\hline Ferrous fumarate & $330 \mathrm{mg} / \mathrm{g}$ \\
\hline Ferrous carbonate, anhydrous & $480 \mathrm{mg} / \mathrm{g}$ \\
\hline Carbonyl iron & $1000 \mathrm{mg} / \mathrm{g}$ \\
\hline
\end{tabular}


Table 2. IV Iron Products: A Comparison

\begin{tabular}{|l|c|c|}
\hline Drug - Name - Manufacture & Concentration & Post-dose Observation Needed \\
\hline HMW-ID (DexFerrum), & $50 \mathrm{mg} / \mathrm{mL}$ & $\begin{array}{c}60 \mathrm{~min} \text { after test dose, } \\
30 \mathrm{~min} \text { after actual dose }\end{array}$ \\
\hline LMW-ID (InFed) & $50 \mathrm{mg} / \mathrm{mL}$ & $\begin{array}{c}60 \mathrm{~min} \text { after test dose, } \\
30 \mathrm{~min} \text { after actual dose }\end{array}$ \\
\hline Ferric gluconate (Ferlixit), & $12.5 \mathrm{mg} / \mathrm{mL}$ & $30 \mathrm{~min}$ \\
\hline Iron sucrose (Venofer), & $20 \mathrm{mg} / \mathrm{mL}$ & $30 \mathrm{~min}$ \\
\hline Ferumoxytol (Feraheme), & $30 \mathrm{mg} / \mathrm{mL}$ & $30 \mathrm{~min}$ \\
\hline Ferric carboxymaltose (Ferinject) & $50 \mathrm{mg} / \mathrm{mL}$ & $30 \mathrm{~min}$ \\
\hline
\end{tabular}

HMW-ID: high-molecular-weight iron dextran; LMW-ID: low-molecular-weight iron dextran;

was a major innovation in the treatment of the anemia of patients with $\mathrm{CKD}$. The development of rHuEPO was aimed at replacing the insufficient EPO production related to CKD progression. Thus, the rHuEPO therapy was considered as a useful therapy for dialysis dependent CKD patients, whose hemoglobin dropped to extremely low levels, making them transfusion-dependent.

The immediate improvement in symptoms of anemia with the administration of rHuEPO in CKD patients was associated with reduced need for blood transfusions, resulting in risk of transmission of bloodborne viral diseases, such as hepatitis B and C, less allosensitization, predispose to long waiting times or failure to receive a kidney transplant, transplant rejection, and reduced risk of hemosiderosis [58]. In many observational studies, the gradually increased and often the normalization of $\mathrm{Hb}$ values, showed an inversely proportional association to certain intermediate outcomes such as left ventricular hypertrophy [8], as well as patient outcomes hard as cardiovascular events hospitalization [59], and death [60].

At the beginning, the use of rHuEPO has been limited to dialysis patients with the most serious forms of anemia. In the following years, its use has been extended to the majority of dialysis patients with renal anemia, and, later, also in anemic patients with CKD 4-5 in countries where the high cost of rHuEPO did not limit number of patients who can benefit from this treatment. In this period, $\mathrm{Hb}$ targets also increased progressively, often into the range of normal values. The idea of a complete correction of anemia was based on improving outcomes in the medium and long term reported in observational studies $[8,59$ 61]. The US Normal Hematocrit Trial by Besarab et al. [16] was the first of a series of randomized controlled trials (RCTs) which cast serious doubt on the assumption that full anemia correction should be achieved in the majority of dialysis patients. Patients who achieve a normal $\mathrm{Hb}$ showed a greater number of myocardial infarcts, primary events and deaths than those in which anemia was partially corrected anemia with epoetin. The study was stopped early due to inability to prove the primary hypothesis.

The double-blind Canada-Europe trial by Parfrey et al. [61] in CKD 5HD patients without symptomatic heart disease (18\% with diabetic nephropathy) failed to demonstrated a beneficial effect on left ventricular volume and mass index in the full anemia correction regime using epoetin-alfa $(\mathrm{Hb}$ target $=13.5-14.5 \mathrm{~g} / \mathrm{dL})$, compared to partial correction one $(\mathrm{Hb}$ target $=9.5-11.5 \mathrm{~g} / \mathrm{dL})$.

In the CREATE study by Drueke et al. [62] in CKD stage 3-5 patients, was not demonstrate a superiority of full anemia correction ( $\mathrm{Hb}$ target=13.0-15.0 $\mathrm{g} / \mathrm{dL}$ ) in terms of cardiovascular events, as compared to partial correction of anemia ( $\mathrm{Hb}$ target $=10.5-11.5 \mathrm{~g} /$ $\mathrm{dL}$ ), when starting ESA therapy at an earlier stage than end-stage renal disease (ESRD) using epoetin-beta. Dialysis therapy was required in significantly more patients in the high $\mathrm{Hb}$ group than in the low $\mathrm{Hb}$ group. However the rate of fall of GFR in the two groups during the 3 year study was similar. Also the US CHOIR study by Singh et al. [63] was prematurely stopped after an interim analysis with a median study duration of 16 months. This study failed to demonstrate a superiority of full anemia correction ( $\mathrm{Hb}$ targets $=13.5 \mathrm{~g} / \mathrm{dL}$ ) by ESA administration in terms of cardiovascular events and death, as compared to partial treatment of anemia ( $\mathrm{Hb}$ targets $=11.3 \mathrm{~g} / \mathrm{dL})$, in patients with CKD 3-4 patients using epoetin alfa.

Finally, the international trial of darbepoetin-alfa in type 2 diabetes and CKD (TREAT) by Pfeffer et al. [64] that examined cardiovascular and kidney outcomes in CKD 3-4 patients, not significant differences were found neither in cardiovascular event and death nor in ESRD, in patients with full anemia correction $(\mathrm{Hb}$ targets $=12.5 \mathrm{~g} / \mathrm{dL}$ ) compared partial treatment of anemia $(\mathrm{Hb}$ targets $=10.6 \mathrm{~g} / \mathrm{dL})$,

Assessment of ESAs in CKD using meta-analysis is problematic because of the heterogeneity of patients entered, the different quality and research designs of the RCTs performed, and differences in definitions of endpoints. The most recent meta-analysis [65] concluded that higher $\mathrm{Hb}$ concentrations in CKD increases risk for stroke, hypertension, and vascular access thrombosis, and may perhaps increase risk for death, serious cardiovascular events or ESRD.

According to the interpretations of the combined results of the recent major RCTs, the target $\mathrm{Hb}$ values exceeding $11.5 \mathrm{~g} / \mathrm{dL}$ in adult CKD patients can cause more harm than benefit. The update of the $2006 \mathrm{KDOQI}$ anemia guideline in 2007, had already led to the recommendation to limit the upper the target $\mathrm{Hb}$ to $12 \mathrm{~g} / \mathrm{dL}$, and do not exceed $13 \mathrm{~g} / \mathrm{dL}$ [23].

Regarding the initiation of therapy ESA, dose adjustments ESA and rates of change, the objective is a rate of increase in $\mathrm{Hb}$ concentrations of 1.0 to $2.0 \mathrm{~g} / \mathrm{dL}$ per month [22]. The $\mathrm{Hb}$ rate of increase varies greatly as a function of individual ESA responsiveness. Poor responders are more likely female, patients with history of cardiovascular disease, iron deficiency and inflammation, and overweight [26]. The response also depends on initial dose, dosing frequency, and route of administration. However, the last two concern epoetin-alfa, epoetinbeta, and darbepoetin but not CERA (continuous erythropoietin receptor activator [methoxy polyethylene glycol-epoetin-beta]). Table 3 compares the different erythropoietin-stimulating agents.

Epoetin-alfa or epoetin-beta dosing usually starts at 20 to $50 \mathrm{IU} /$ $\mathrm{kg}$ body weight three times a week. Darbepoetin-alfa dosing usually starts at $0.45 \mathrm{mg} / \mathrm{kg}$ body weight once weekly by subcutaneous (SC) or IV administration, or $0.75 \mathrm{mg} / \mathrm{kg}$ body weight once every 2 weeks by SC administration. CERA dosing starts at $0.6 \mathrm{mg} / \mathrm{kg}$ body weight once every 2 weeks by SC or IV administration for CKD ND and CKD 5D patients, respectively, or $1.2 \mathrm{mg} / \mathrm{kg}$ body weight once every 4

Table 3. Comparison between erythropoietin-stimulating agents.

\begin{tabular}{|l|l|l|l|}
\hline & Brand & Half-life & FDA approval \\
\hline Erythtopoietin alpha & $\begin{array}{l}\text { Epogen } \\
\text { Procrit } \\
\text { Eprex }\end{array}$ & $\begin{array}{l}\text { IV: } 4-13 \mathrm{hs} \\
\text { SC: } 13-37 \mathrm{hs}\end{array}$ & Approved \\
\hline Erythtopoietin beta & NeoRecormon & $\begin{array}{l}\text { IV: } 4-12 \mathrm{hs} \\
\text { SC: } 8-22 \mathrm{hs}\end{array}$ & Approved in Europe \\
\hline Darbepoietin & Aranesp & $\begin{array}{l}\text { IV: } 23-39 \mathrm{hs} \\
\text { SC: } 21-144 \mathrm{hs}\end{array}$ & Approved \\
\hline C.E.R.A. & Mircera & $\begin{array}{l}\text { IV: } 4-134 \mathrm{hs} \\
\text { SC: } 21-144 \mathrm{hs}\end{array}$ & Approved \\
\hline
\end{tabular}

C.E.R.A. $=$ methoxy polyethylene glycol-epoetin-beta 
weeks by SC administration for CKD ND patients. Higher baseline $\mathrm{Hb}$ concentrations require lower initial ESA doses, except for CERA for which there is no initial dose change.

However, ESA requirements should be evaluated or reevaluated each time a patients with CKD is hospitalized. ESA responsiveness may be modified profoundly during Disease states such as severe infections or postsurgery.

In recent years, the scenario of ESA has become complex due to the appearance of biosimilars epoetin in trying to contain production costs.

The European Union is currently the most advanced region in terms of having a developed regulatory pathway for biosimilar products. Medicines legislation creating the regulatory pathway for biosimilars was introduced in Europe in 2004. The European Medicines Agency (EMA)/Committee for Human Medicinal Products (CHMP) issued an overarching biosimilars guideline [66]. To obtain marketing authorization for a biosimilar, comparative quality studies with an approved reference epoetin, and non-clinical and clinical safety and efficacy studies are required. Two biosimilar epoetins (substances HX575 and SB309) proved sufficient analogy to the innovator epoetin alfa $\left(\right.$ Eprex $^{\oplus} /$ Erypo $\left.^{\circ}\right)$ in preclinical and clinical studies according to the EU guidelines. HX575 has been approved under three different trade names: Binocrit ${ }^{\circledast}$ (Sandoz), Epoetin alfa Hexal ${ }^{\circledR}$ (Hexal Biotech) and Abseamed ${ }^{\oplus}$ (Medice Arzneimittel Putter). These co-marketed products are true 'bioidenticals' which may be substituted among themselves. Epoietin zeta or SB309 has been approved under two different trade names: Silapo ${ }^{\oplus}$ (Stada) and Retacrit ${ }^{\oplus}$ (Hospira), which are bioidenticals among themselves.

The Australian Therapeutic Goods Administration (TGA) has approved the 'epoetin lambda' (Novicrit', Novartis Pharm, Australia) with sufficient analogy to the epoetin alfa. An 'epoetin kappa' has been available in Japan since 2010, which was approved as a biosimilar to epoetin alfa. However, the isoelectric and isoform profile of epoetin kappa differs greatly from the profile of other epoetins. In 2009, S. Korea released a draft guidance on biosimilars and in the same year Singapore's drug regulation agency, the Health Sciences Authority (HSA), issued guidelines on the regulatory registration of biosimilars, which was mainly adapted from EMA biosimilar guidelines.

It is interesting to note that the naming of the various epoetins can differ between regions in the world (Table 4).

\section{Red cell transfusion to treat anemia in CKD}

After the addition of ESAs to available treatments for anemia in CKD patients, there has been a marked decline in transfusion events in this population. Current anemia management guidelines recommend reaching the $\mathrm{Hb}$ target using the lowest possible ESA dosages to avoid the need for red blood cell transfusions [22]. Although transfusions

Table 4. Comparison between biosimilar-epoietin.

\begin{tabular}{|c|c|c|c|}
\hline & Brand & Half-life & FDA approval \\
\hline Erythtopoietin alpha & $\begin{array}{c}\text { Binocrit } \\
\text { Epoietin Alfa Hexal } \\
\text { Abseamed }\end{array}$ & $\begin{array}{l}\text { IV: } 4-13 \mathrm{hs} \\
\text { SC: } 13-30 \mathrm{hs}\end{array}$ & $\begin{array}{l}\text { Approved in } \\
\text { European Union }\end{array}$ \\
\hline Erythtopoietin zeta & $\begin{array}{c}\text { Silapo } \\
\text { Retacrit }\end{array}$ & $\begin{array}{l}\text { IV: } 4-12 \mathrm{hs} \\
\text { SC: } 8-20 \mathrm{hs}\end{array}$ & $\begin{array}{c}\text { Approved in } \\
\text { European Union }\end{array}$ \\
\hline Epoietin lambda & Novicrit & $\begin{array}{l}\text { IV: } 5-12 \mathrm{hs} \\
\text { SC: } 6-15 \mathrm{hs}\end{array}$ & $\begin{array}{l}\text { Approved in } \\
\text { Australia }\end{array}$ \\
\hline Epoietin kappa & JR-013 JCR & $\begin{array}{l}\text { IV: } 4-14 \mathrm{hs} \\
\text { SC: } 5-20 \mathrm{hs}\end{array}$ & $\begin{array}{l}\text { Approved } \\
\text { in Japan }\end{array}$ \\
\hline
\end{tabular}

provide a rapid primary benefits of maintaining a sufficient oxygen carrying capacity improving anemia-related symptoms, and are considerably safer than in the past, transfusion-related risks persist.

Risks associated with blood transfusion include transfusion errors, volume and iron overload, hyperkalemia, citrate toxicity (leading to metabolic alkalosis and hypocalcemia), hypothermia, coagulopathy and immunologically-mediated transfusion reactions, all of which are uncommon. The most significant current risk of mortality from blood transfusion due to administrative error results in hemolysis (one in 60,000 ) and death (one in 600,000) [67].

The development of antibodies to human leukocytes antigen (HLA), can affect a patient's ability to receive organ transplants [68]. The risk of HLA sensitization after blood transfusion has changed over time probably, at least in part, due to changes in blood transfusion practices and the use of more precise methods to measure allosensitization. HLA sensitization was associated with several factors such as previous pregnancies and previous transplantation. Available data suggest that men have a much lower risk of HLA sensitization following transfusion than women, and women with multiple pregnancies have a much greater risk of HLA sensitization than nulliparous women. However, more recent data from the US Renal Data System (USRDS) 2010 Annual Report, [69] have challenged this assumption, suggesting that males receiving previous blood transfusions may also be at increased risk.

One of the most easily identifiable cause of transfusion-related morbidity and mortality in the United States is the transfusion-related acute lung injury (TRALI) [70]. However, because of the varied criteria used to diagnose this syndrome, the true incidence is not known. Estimated incidence of TRALI is 8 cases per 100000 units of blood components transfused. Risk factors for TRALI are age and illness severity, and the risk for development of TRALI increases with the number of units transfused. TRALI is characterized by pulmonary edema, hypoxemia, respiratory distress, and radiographic evidence of new bilateral pulmonary infiltrates occurring within minutes to 6 hours after transfusion. Fever, tachycardia, cyanosis, hypotension, and frothy sputum may also be present.

Risks of transfusion transmitted viral infections are extremely low, currently estimated to be approximately one in $1.4 \times 106$ to $2.4 \times 106$ units for human immunodeficiency virus (HIV), one in 872,000 to 1.7 x 106 for hepatitis C virus (HCV), and one in 58,000 to 149,000 for hepatitis B virus (HBV) [71]. Rigorous predonation screening has led to a rapid decline in prevalence of HIV and HCV in first time blood donors, with HIV decreasing from $0.03 \%$ (1991-1992) to $0.02 \%$ (19931996 ) and HCV decreasing from $0.63 \%$ (1992) to $0.40 \%$ (1996), despite an increase in prevalence in the general population for both HIV $(0.3 \%$ in 1992) and HCV (1.8\% in 1988-1994) [72]. The introduction of nucleic acid amplification testing (NAT) for HIV and HCV in 1999, further reduced the window period between a potential blood donor infection and detectability by screening tests at time of donation [73].

Certain urgent clinical situations as well as acute severe hemorrhage and unstable coronary artery disease, red cell transfusion may be needed for the immediate correction of anemia. Also urgent situation where surgery is required, transfusion may also be given to achieve rapid preoperative correction of $\mathrm{Hb}$. In stable $\mathrm{CKD}$ patients, transfusion should be considered when ESAs are ineffective in the treatment of chronic anemia (hemoglobinopathies, bone marrow failure, ESA resistance). In all these situations, the $\mathrm{Hb}$ threshold for transfusion is uncertain but the treatment should be considered when the $\mathrm{Hb}$ is $<7 \mathrm{~g} / \mathrm{dL}$ (Table 5). 
Table 5. Clinical indications for red cell transfusion in Chronic Kidney Diseases patients.

\begin{tabular}{|l|l|}
\hline Acute clinical situations & Chronic clinical situations \\
\hline Acute severe hemorrhage & $\begin{array}{l}\text { Chronic anemia and ESAs are ineffective } \\
\text { (hemoglobinopathies, bone marrow failure, } \\
\text { ESA resistance) }\end{array}$ \\
\hline $\begin{array}{l}\text { Unstable coronary artery disease } \\
\text { When rapid preoperative anemia correction } \\
\text { is required }\end{array}$ & \\
\hline ESA: erythropoiesis-stimulating agent &
\end{tabular}

ESA: erythropoiesis-stimulating agent

\section{Conclusion}

Anemia is a frequent complication in CKD, and it is often accompanied by various clinical symptoms, morbidity, and prognosis associated with reduced kidney function determining poor quality of life.

Anemia might begin to develop in the early stages of CKD, with a reduction of 20 to 50 percent of normal kidney function, and tends to worsen as CKD progresses.

The etiology of CKD-related anemia is multifactorial. The main cause is the deficiency in the production of erythropoietin, with the consequent reduction of red blood cells by the bone marrow, inducing a deprivation of oxygen levels in the blood that causing anemia. Other common causes of CKD-related anemia include blood loss from hemodialysis and low levels of iron, vitamin B12 and folic acid.

In all CKD patients, complete blood count, hemoglobin and hematocrit concentration, mean corpuscular volume, reticulocyte count, vitamin B12, folic acid, and iron status (determination of ferritin, and TSAT) should be measured as part of anemia workup. Inflammatory markers determination, as well as high sensitivity C-reactive protein may help in etiological framework.

Iron deficiency, should be treated and its causes established. It is possible to supplement iron orally or intravenously, while it is not recommended the use of intramuscular via. Since each administration route presents potential advantages and limitations, a careful evaluation should be performed in any patient to be treated.

If $\mathrm{Hb}$ is less than $11 \mathrm{~g} / \mathrm{dL}$, ESA therapy initiation should be discussed with the patient with focus on potential risks and benefits. It appears from available data that higher $\mathrm{Hb}$ targets are not beneficial and potentially harmful. Current K-DOQI guidelines advise for a $\mathrm{Hb}$ target of 11 to $12 \mathrm{~g} / \mathrm{dL}$ without exceeding $13 \mathrm{~g} / \mathrm{dL}$. Laboratory testing should be repeated monthly until ESA dose is stable. Hb level and iron markers should be followed every 3 months during stable ESA treatment.

Red blood cells transfusion in CKD patients should be avoided as much as possible. It is well known that transfusions may induce the formation of HLA antibodies that can reduce the success of future kidney transplantation. In addition, transfusions may cause hypervolemia and symptoms of congestive heart failure, particularly in elderly patients. The K-DOQI guidelines state that no single $\mathrm{Hb}$ level should justify or require transfusion. Risks and benefits of transfusion therapy should be considered in individualized patients.

\section{References}

1. WHO (1968) Nutritional anaemias. Report of a WHO scientific group. World Health Organ Tech Rep Ser 405: 5-37. [Crossref]

2. Astor BC, Muntner P, Levin A, Eustace JA, Coresh J (2002) Association of kidney function with anemia: the Third National Health and Nutrition Examination Survey (1988-1994). Arch Intern Med 162: 1401-1408. [Crossref]

3. Smith RE Jr (2010) The clinical and economic burden of anemia. Am J Manag Care 16 Suppl Issues: S59-66. [Crossref]
4. Kazmi WH, Kausz AT, Khan S, Abichandani R, Ruthazer R, et al. (2001) Anemia: an early complication of chronic renal insufficiency. Am J Kidney Dis 38: 803-812. [Crossref]

5. Obrador GT, Ruthazer R, Arora P, Kausz AT, Pereira BJ (1999) Prevalence of and factors associated with suboptimal care before initiation of dialysis in the United States. J Am Soc Nephrol 10: 1793-1800. [Crossref]

6. Centers for Disease Control and Prevention (CDC) (2007) Prevalence of chronic kidney disease and associated risk factors--United States, 1999-2004. MMWR Morb Mortal Wkly Rep 56: 161-165. [Crossref]

7. National Kidney Disease Education Program (NKDEP) [Internet]. [cited 2015 Oct 11].

8. Levin A, Thompson CR, Ethier J, Carlisle EJ, Tobe S, et al. (1999) Left ventricular mass index increase in early renal disease: impact of decline in hemoglobin. $\mathrm{Am} \mathrm{J}$ Kidney Dis 34: 125-134. [Crossref]

9. Jurkovitz CT, Abramson JL, Vaccarino LV, Weintraub WS, McClellan WM (2003) Association of high serum creatinine and anemia increases the risk of coronary events: results from the prospective community-based atherosclerosis risk in communities (ARIC) study. J Am Soc Nephrol JASN 14: 2919-2925.

10. Sarnak MJ, Tighiouart H, Manjunath G, MacLeod B, Griffith J, et al. (2002) Anemia as a risk factor for cardiovascular disease in The Atherosclerosis Risk in Communities (ARIC) study. J Am Coll Cardiol 40: 27-33. [Crossref]

11. Abramson JL, Jurkovitz CT, Vaccarino V, Weintraub WS, McClellan W (2003) Chronic kidney disease, anemia, and incident stroke in a middle-aged, communitybased population: the ARIC Study. Kidney Int 64: 610-615. [Crossref]

12. Xia H, Ebben J, Ma JZ, Collins AJ (1999) Hematocrit levels and hospitalization risks in hemodialysis patients. J Am Soc Nephrol 10: 1309-1316. [Crossref]

13. Collins AJ, Li S, St Peter W, Ebben J, Roberts T, et al. (2001) Death, hospitalization, and economic associations among incident hemodialysis patients with hematocrit values of 36 to 39\%. J Am Soc Nephrol JASN 12: 2465-2473.

14. Weiss G, Goodnough LT (2005) Anemia of chronic disease. N Engl J Med 352: 10111023. [Crossref]

15. Research C for DE and. Drug Safety and Availability - FDA Drug Safety Communication: Modified dosing recommendations to improve the safe use of Erythropoiesis-Stimulating Agents (ESAs) in chronic kidney disease [Internet]. [cited 2015 Oct 11]

16. Besarab A, Bolton WK, Browne JK, Egrie JC, Nissenson AR, et al. (1998) The effects of normal as compared with low hematocrit values in patients with cardiac disease who are receiving hemodialysis and epoetin. $N$ Engl J Med 339: 584-590. [Crossref]

17. Pfeffer MA, Burdmann EA, Chen CY, Cooper ME, de Zeeuw D, et al. (2009) A trial of darbepoetin alfa in type 2 diabetes and chronic kidney disease. N Engl J Med 361: 2019-2032. [Crossref]

18. Phrommintikul A, Haas SJ, Elsik M, Krum H (2007) Mortality and target haemoglobin concentrations in anaemic patients with chronic kidney disease treated with erythropoietin: a meta-analysis. Lancet Lond Engl 369: 381-388.

19. Strippoli GF, Craig JC, Manno C, Schena FP (2004) Hemoglobin targets for the anemia of chronic kidney disease: a meta-analysis of randomized, controlled trials. $J$ Am Soc Nephrol 15: 3154-3165. [Crossref]

20. NKF-DOQI clinical practice guidelines for the treatment of anemia of chronic renal failure. National Kidney Foundation-Dialysis Outcomes Quality Initiative. Am J Kidney Dis Off J Natl Kidney Found 1997 30: S192-240.

21. [No authors listed] (2001) IV. NKF-K/DOQI Clinical Practice Guidelines for Anemia of Chronic Kidney Disease: update 2000. Am J Kidney Dis 37: S182-238. [Crossref]

22. KDOQI, National Kidney Foundation. KDOQI Clinical Practice Guidelines and Clinical Practice Recommendations for Anemia in Chronic Kidney Disease. Am J Kidney Dis Off J Natl Kidney Found 2006 47: S11-145.

23. KDOQI. KDOQI Clinical Practice Guideline and Clinical Practice Recommendation for anemia in chronic kidney disease: 2007 update of hemoglobin target. Am J Kidney Dis Off J Natl Kidney Found 2007 50: 471-530.

24. [No authors listed] (2012) Chapter 1: Diagnosis and evaluation of anemia in CKD Kidney Int Suppl (2011) 2: 288-291. [Crossref]

25. Lipschitz DA, Cook JD, Finch CA (1974) A clinical evaluation of serum ferritin as an index of iron stores. N Engl J Med 290: 1213-1216. [Crossref]

26. Rambod M1, Kovesdy CP, Kalantar-Zadeh K (2008) Combined high serum ferritin and low iron saturation in hemodialysis patients: the role of inflammation. Clin J Am Soc 


\section{Nephrol 3: 1691-1701. [Crossref]}

27. Kalantar-Zadeh K, Höffken B, Wünsch H, Fink H, Kleiner M, et al. (1995) Diagnosis of iron deficiency anemia in renal failure patients during the post-erythropoietin era. Am J Kidney Dis 26: 292-299. [Crossref]

28. Fernández-Rodríguez AM, Guindeo-Casasús MC, Molero-Labarta T, DomínguezCabrera C, Hortal-Case n L, (1999) et al. Diagnosis of iron deficiency in chronic renal failure. Am J Kidney Dis Off J Natl Kidney Found 34: 508-513.

29. DeVita MV, Frumkin D, Mittal S, Kamran A, Fishbane S, et al. (2003) Targeting higher ferritin concentrations with intravenous iron dextran lowers erythropoietin requirement in hemodialysis patients. Clin Nephrol 60: 335-340. [Crossref]

30. Nicolas G, Viatte L, Bennoun M, Beaumont C, Kahn A, et al. (2002) Hepcidin, a new iron regulatory peptide. Blood Cells Mol Dis 29: 327-335. [Crossref]

31. Zaritsky J, Young B, Gales B, Wang HJ, Rastogi A, et al. (2010) Reduction of serum hepcidin by hemodialysis in pediatric and adult patients. Clin J Am Soc Nephrol 5: 1010-1014. [Crossref]

32. Kato A, Tsuji T, Luo J, Sakao Y, Yasuda H, et al. (2008) Association of prohepcidin and hepcidin-25 with erythropoietin response and ferritin in hemodialysis patients. $\mathrm{Am}$ J Nephrol 28: 115-121. [Crossref]

33. Tessitore N, Girelli D, Campostrini N, Bedogna V, Pietro Solero G, et al. (2010) Hepcidin is not useful as a biomarker for iron needs in haemodialysis patients on maintenance erythropoiesis-stimulating agents. Nephrol Dial Transplant 25: 3996 4002. [Crossref]

34. Macdougall IC (1994) Monitoring of iron status and iron supplementation in patients treated with erythropoietin. Curr Opin Nephrol Hypertens 3: 620-625. [Crossref]

35. Mircescu G, Gârneata L, Capusa C, Ursea N (2006) Intravenous iron supplementation for the treatment of anaemia in pre-dialyzed chronic renal failure patients. Nephrol Dial Transplant 21: 120-124. [Crossref]

36. Silverberg DS, Iaina A, Peer G, Kaplan E, Levi BA, et al. (1996) Intravenous iron supplementation for the treatment of the anemia of moderate to severe chronic renal failure patients not receiving dialysis. Am J Kidney Dis 27: 234-238. [Crossref]

37. Spinowitz BS, Kausz AT, Baptista J, Noble SD, Sothinathan R, et al. (2008) Ferumoxytol for treating iron deficiency anemia in CKD. J Am Soc Nephrol 19: 15991605. [Crossref]

38. Silverberg DS1, Blum M, Agbaria Z, Deutsch V, Irony M, et al. (2001) The effect of i.v. iron alone or in combination with low-dose erythropoietin in the rapid correction of anemia of chronic renal failure in the predialysis period. Clin Nephrol 55: 212-219. [Crossref]

39. Stancu S, Bârsan L, Stanciu A, Mircescu G (2010) Can the response to iron therapy be predicted in anemic nondialysis patients with chronic kidney disease? Clin J Am Soc Nephrol 5: 409-416. [Crossref]

40. Tessitore N, Solero GP, Lippi G, Bassi A, Faccini GB, et al. (2001) The role of iron status markers in predicting response to intravenous iron in haemodialysis patients on maintenance erythropoietin. Nephrol Dial Transplant Off Publ Eur Dial Transpl Assoc - Eur Ren Assoc 16: 1416-1423.

41. Macdougall IC (1999) Strategies for iron supplementation: oral versus intravenous. Kidney Int Suppl 69: S61-66. [Crossref]

42. Rampton D, Folkersen J, Fishbane S, Hedenus M, Howaldt S, et al. (2014) Hypersensitivity reactions to intravenous iron: guidance for risk minimization and management. Haematologica 99: 1671-1676. [Crossref]

43. Behera V, Chauhan R, Sinha S, Nair V (2015) Anaphylactic Shock Secondary to Intravenous Iron Sucrose in Chronic Kidney Disease. Indian J Hematol Blood Transfus Off J Indian Soc Hematol Blood Transfus 31: 391-393.

44. Bailie GR, Verhoef JJ (2012) Differences in the reporting rates of serious allergic adverse events from intravenous iron by country and population. Clin Adv Hematol Oncol 10: 101-108. [Crossref]

45. Bircher AJ, Auerbach M (2014) Hypersensitivity from intravenous iron products. Immunol Allergy Clin North Am 34: 707-723, x-xi. [Crossref]

46. Auerbach M, Adamson J, Bircher A, Breymann C, Fishbane S, et al. (2015) On the safety of intravenous iron, evidence trumps conjecture. Haematologica 100: e214-215. [Crossref]

47. Litton E, Xiao J, Ho KM (2013) Safety and efficacy of intravenous iron therapy in reducing requirement for allogeneic blood transfusion: systematic review and metaanalysis of randomised clinical trials. BMJ 347: f4822. [Crossref]
48. Allegra V, Mengozzi G, Vasile A (1991) Iron deficiency in maintenance hemodialysis patients: assessment of diagnosis criteria and of three different iron treatments. Nephron 57: 175-182. [Crossref]

49. Macdougall IC, Tucker B, Thompson J, Tomson CR, Baker LR, et al. (1996) A randomized controlled study of iron supplementation in patients treated with erythropoietin. Kidney Int 50: 1694-1699. [Crossref]

50. Albaramki J, Hodson EM, Craig JC, Webster AC (2012) Parenteral versus oral iron therapy for adults and children with chronic kidney disease. Cochrane Database Syst Rev 1: CD007857. [Crossref]

51. Susantitaphong P, Alqahtani F, Jaber BL (2014) Efficacy and safety of intravenous iron therapy for functional iron deficiency anemia in hemodialysis patients: a meta-analysis. Am J Nephrol 39: 130-141. [Crossref]

52. Van Wyck DB, Roppolo M, Martinez CO, Mazey RM, McMurray S (2005) A randomized, controlled trial comparing IV iron sucrose to oral iron in anemic patient with nondialysis-dependent CKD. Kidney Int 68: 2846-2856.

53. Charytan C, Qunibi W, Bailie GR; Venofer Clinical Studies Group (2005) Comparison of intravenous iron sucrose to oral iron in the treatment of anemic patients with chronic kidney disease not on dialysis. Nephron Clin Pract 100: c55-62. [Crossref]

54. Agarwal R, Rizkala AR, Bastani B, Kaskas MO, Leehey DJ, et al. (2006) A randomized controlled trial of oral versus intravenous iron in chronic kidney disease. Am J Nephrol 26: 445-454. [Crossref]

55. Chertow GM, Mason PD, Vaage-Nilsen O, Ahlmén J (2006) Update on adverse drug events associated with parenteral iron. Nephrol Dial Transplant 21: 378-382. [Crossref]

56. Auerbach M, Ballard H (2010) Clinical use of intravenous iron: administration, efficacy, and safety. Hematology Am Soc Hematol Educ Program 2010: 338-347. [Crossref]

57. Bernhardt WM, Wiesener MS, Scigalla P, Chou J, Schmieder RE, et al. (2010) Inhibition of prolyl hydroxylases increases erythropoietin production in ESRD. $J \mathrm{Am}$ Soc Nephrol 21: 2151-2156. [Crossref]

58. Goodnough LT, Brecher ME, Kanter MH, AuBuchon JP (1999) Transfusion medicine. First of two parts--blood transfusion. $N$ Engl J Med 340: 438-447. [Crossref]

59. Harnett JD, Foley RN, Kent GM, Barre PE, Murray D, et al. (1995) Congestive heart failure in dialysis patients: prevalence, incidence, prognosis and risk factors. Kidney Int 47: 884-890.

60. Collins AJ (2002) Influence of target hemoglobin in dialysis patients on morbidity and mortality. Kidney Int Suppl : 44-48. [Crossref]

61. Parfrey PS, Foley RN, Wittreich BH, Sullivan DJ, Zagari MJ, et al. (2005) Doubleblind comparison of full and partial anemia correction in incident hemodialysis patients without symptomatic heart disease. J Am Soc Nephrol 16: 2180-2189. [Crossref]

62. Drüeke TB, Locatelli F, Clyne N, Eckardt KU, Macdougall IC, et al. (2006) Normalization of hemoglobin level in patients with chronic kidney disease and anemia N Engl J Med 355: 2071-2084. [Crossref]

63. Singh AK, Szczech L, Tang KL, Barnhart H, Sapp S, et al. (2006) Correction of anemi with epoetin alfa in chronic kidney disease. $N$ Engl J Med 355: 2085-2098. [Crossref]

64. Pfeffer MA, Burdmann EA, Chen CY, Cooper ME, de Zeeuw D, et al. (2009) A trial of darbepoetin alfa in type 2 diabetes and chronic kidney disease. $N$ Engl J Med 361: 2019-2032. [Crossref]

65. Palmer SC, Navaneethan SD, Craig JC, Johnson DW, Tonelli M, et al. (2010) Metaanalysis: erythropoiesis-stimulating agents in patients with chronic kidney disease. Ann Intern Med 153: 23-33. [Crossref]

66. European Medicines Agency - Biologicals - Similar biological medicinal products [Internet]. [cited 2016 Aug 31].

67. Linden JV, Tourault MA, Scribner CL (1997) Decrease in frequency of transfusion fatalities. Transfusion 37: 243-244. [Crossref]

68. Opelz G, Graver B, Mickey MR, Terasaki PI (1981) Lymphocytotoxic antibody responses to transfusions in potential kidney transplant recipients. Transplantation 32: 177-183. [Crossref]

69. Collins AJ, Foley RN, Chavers B, Gilbertson D, Herzog C, et al. (2012) United States Renal Data System 2011 Annual Data Report: Atlas of chronic kidney disease \& endstage renal disease in the United States. Am J Kidney Dis Off J Natl Kidney Found 59: e1-420.

70. Looney MR, Gropper MA, Matthay MA (2004) Transfusion-related acute lung injury: a review. Chest 126: 249-258. [Crossref] 
Rivera RF (2016) Anemia in patients with chronic kidney disease: current screening and management approaches

71. Goodnough LT, Brecher ME, Kanter MH, AuBuchon JP (1999) Transfusion medicine. First of two parts--blood transfusion. N Engl J Med 340: 438-447. [Crossref]

72. Glynn SA, Kleinman SH, Schreiber GB, Busch MP, Wright DJ, et al. (2000) Trends in incidence and prevalence of major transfusion-transmissible viral infections in US blood donors, 1991 to 1996. Retrovirus Epidemiology Donor Study (REDS). JAMA 284: $229-235$

73. Dodd RY, Notari EP, Stramer SL (2002) Current prevalence and incidence of infectious disease markers and estimated window-period risk in the American Red Cross blood donor population. Transfusion (Paris) 42: 975-979.

Copyright: (C2016 Rivera RF. This is an open-access article distributed under the terms of the Creative Commons Attribution License, which permits unrestricted use, distribution, and reproduction in any medium, provided the original author and source are credited. 